\title{
Endoscopic management of a perforated gallbladder
}

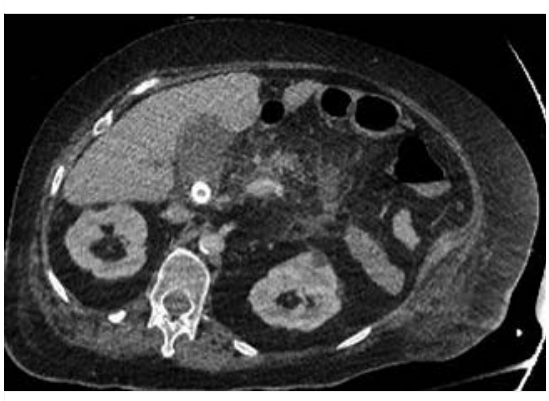

- Fig. 1 Computed tomography showed a distended gallbladder with a large stone.

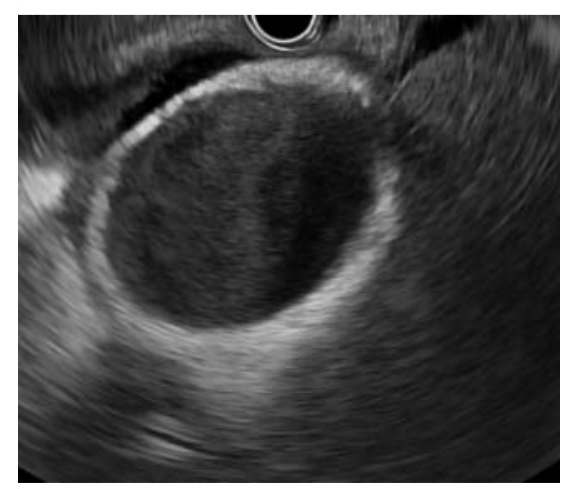

Fig. 2 Endoscopic ultrasound showed free fluid around the gallbladder, consistent with a perforated gallbladder.

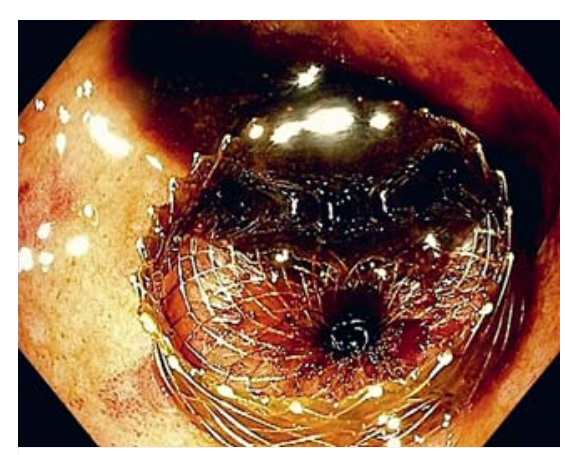

- Fig. 3 Endoscopic image showing a lumen-apposing metal stent, which was placed in a transduodenal approach into the gallbladder at a site of intact wall.

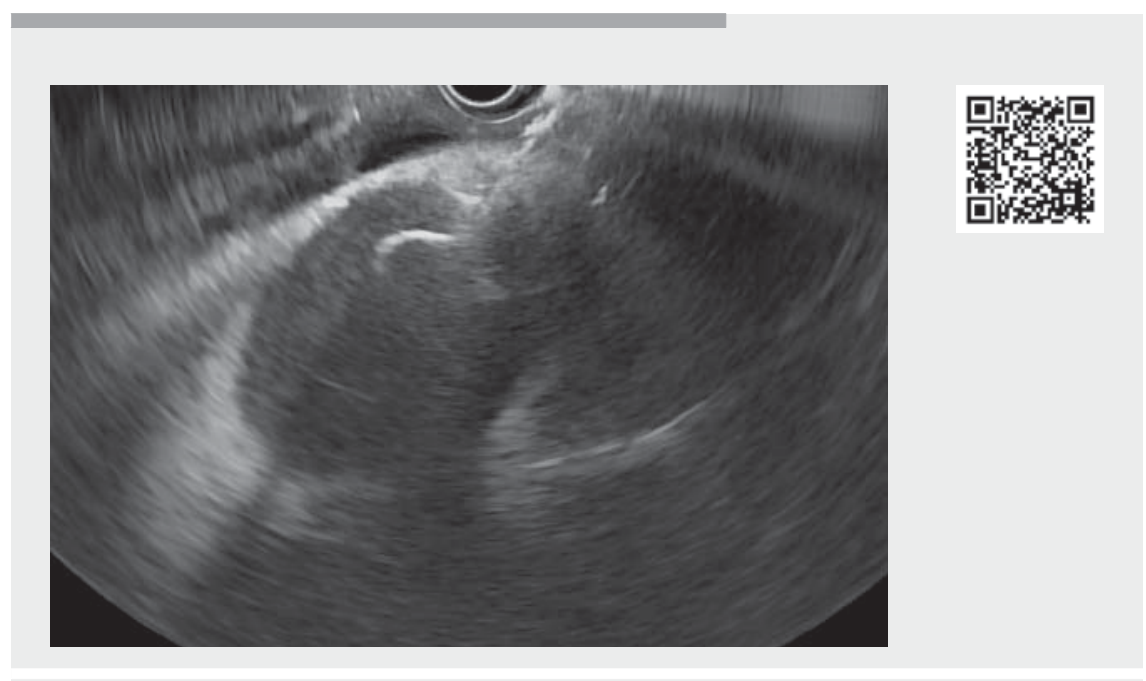

$\checkmark$ Video 1 Endoscopic management of a perforated gallbladder.

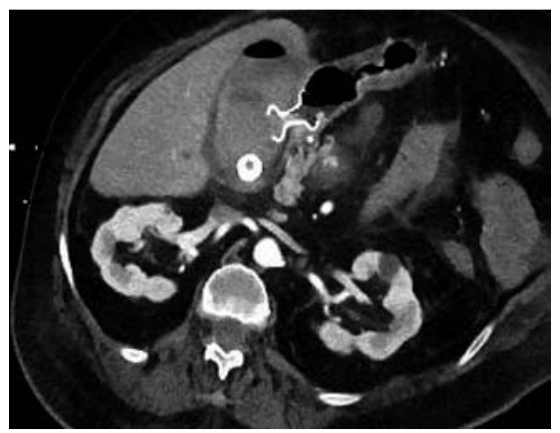

Fig. 4 Computed tomography scan after the procedure confirmed a perforated gallbladder.

An 88-year-old woman with obesity (body mass index $40 \mathrm{~kg} / \mathrm{m}^{2}$ ), diabetes, and heart failure presented with acute cholecystitis. Computed tomography (CT) showed a distended gallbladder with a large stone ( $\mathbf{F i g . 1}$ ). She was started on intravenous fluids and antibiotics. After 5 hours into her admission, she began to become lethargic and had increasing tachycardia. The patient was deemed a nonsurgical candidate owing to her comorbidities and age. Given the recent evidence [1], the patient was referred for endoscopic ultrasound (EUS)-

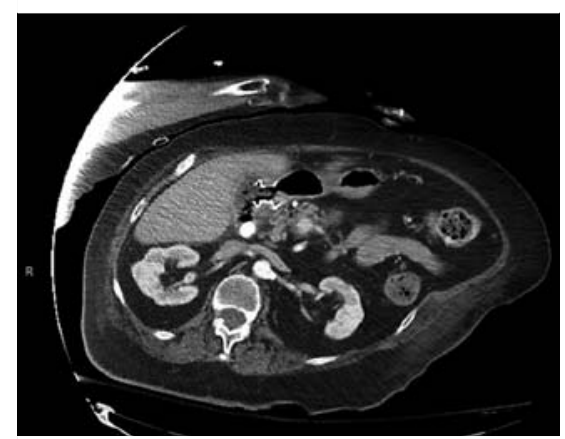

- Fig. 5 Computed tomography scan 8 weeks after the procedure showing resolution of a perforated gallbladder.

guided drainage after multidisciplinary discussion.

On EUS, free fluid was noted around the gallbladder, which was consistent with a perforated gallbladder ( $>$ Fig. 2 , - Video 1) and explained the clinical deterioration. The decision was made to drain the gallbladder where the gallbladder wall was intact. A $10 \times 10$ mm lumenapposing metal stent (LAMS) was placed into the gallbladder through a site of intact wall in a transduodenal approach (\$ Fig.3). Repeat CT scan was performed after the procedure given the suspicion of 
a perforated gallbladder, and confirmed the diagnosis ( $\mathbf{F i g . 4}$ ). The LAMS was positioned away from the perforation on $\mathrm{CT}$ and was in place in the gallbladder. The patient was discharged 7 days later with resolution of symptoms and normalization of laboratory values.

CT scan at 8 weeks showed resolution of the gallbladder perforation, with the LAMS in place (> Fig.5). Endoscopy was performed, and the stent and gallstone were removed. Contrast was injected into the gallbladder and showed no further filling defects in the entire biliary system. On 4-week follow-up the patient was doing well without any symptoms.

This case demonstrates that EUS-guided drainage can be effective in patients with acute cholecystitis who are unsuitable for surgery, even when a perforated gallbladder is suspected. It is important to place the LAMS at a site of intact gallbladder wall.

Endoscopy_UCTN_Code_CCL_1AF_2AF_3AB

Competing interests

Arvind J. Trindade is a consultant for Olympus America and Pentax Medical, and has received research support from Ninepoint Medical. Petros C. Benias is a consultant for Olympus America, Pentax Medical, Creo Medical, Apollo Overstitch, and FujiFilm. The remaining authors declare that they have no conflict of interest.
The authors

Arvind J. Trindade ${ }^{1}$, Mohammed Alshelleh ${ }^{1}$, Nichol Martinez ${ }^{1}$, Anam Rizvi ${ }^{1}$, Petros C.

Benias ${ }^{1}$, Stephen Litvak ${ }^{2}$

1 Division of Gastroenterology, Long Island Jewish Medical Center, Zucker School of Medicine at Hofstra/Northwell, Northwell Health System, New Hyde Park, New York, United States

2 Department of Surgery, Long Island Jewish Medical Center, Zucker School of Medicine at Hofstra/Northwell, Northwell Health System, New Hyde Park, New York, United States

\section{Corresponding author}

\section{Arvind J. Trindade, MD}

Division of Gastroenterology, Long Island Jewish Medical Center, Zucker School of Medicine at Hofstra/Northwell, Northwell Health System, 270-05 76th Avenue, New Hyde Park, NY 11040, United States arvind.trindade@gmail.com

\section{Reference}

[1] Teoh AYB, Kitano M, Itoi T et al. Endosonography-guided gallbladder drainage versus percutaneous cholecystostomy in very highrisk surgical patients with acute cholecystitis: an international randomised multicentre controlled superiority trial (DRAC 1). Gut 2020; 69: 1085-1091
Bibliography

Endoscopy 2022; 54: E396-E397

DOI 10.1055/a-1554-4660

ISSN 0013-726X

published online 27.8.2021

(c) 2021. Thieme. All rights reserved.

Georg Thieme Verlag KG, Rüdigerstraße 14,

70469 Stuttgart, Germany

ENDOSCOPY E-VIDEOS

https://eref.thieme.de/e-videos

回的回 Endoscopy E-Videos is an open access online section, 靣解: reporting on interesting cases and new techniques in gastroenterological endoscopy. All papers include a high quality video and all contributions are freely accessible online. Processing charges apply (currently EUR 375), discounts and wavers acc. to HINARI are available.

This section has its own submission website at https://mc.manuscriptcentral.com/e-videos 